\section{EDUCATION AND TRAINING OF GRADUATE STAFF FOR INDUSTRIAL RESEARCH}

\footnotetext{
$T$
} HE education and training of graduate staff for industrial research was the subject of the fourth Conference of Industrial Research Directors and Managers, which was organized by the Industrial Research Committee of the Federation of British Industries under the chairmanship of Mr. A. H. Wilson, and held at Ashorne Hill, Leamington Spa, during April 29-May 1. The Conference was attended by more than a hundred industrialists and some forty representatives of science or technology from the universities. Sir Graham Hayman, president of the Federation, acted as chairman, and Mr. George Withers, secretary of the Industrial Research Committee, acted as secretary of the Conference.

In the opening session, Sir Edward Bullard (National Physical Laboratory, Teddington) spoke on staffing and managing a research department. He reminded the Conference that in a little more than thirty years research has grown from the pursuit of the individual scientist into an organized business. But training in science still develops an individual approach, and in consequence there can be psychological difficulties when the young scientist becomes a member of a large research department. This, and many other points in Sir Edward's address, were taken up in later sessions.

First-degree courses in science and technology, which was the subject of the second session, may not now offer much scope for original thought; but Prof. E. G. Cox (Leeds) and Prof. J. A. Pope (Nottingham), the two introductory speakers, were not expected to do more than suggest lines of approach which the Conference might consider in discussion groups. In the event, it proved that the discussion groups had interpreted the subject liberally. Clear thinking, a good grasp of fundamentals, and the ability to write straightforward reports are the usual virtues expected. of good first-degree students, while the avoidance of undue specialization and the continual pruning of overloaded curricula are characteristics of good firstdegree courses. There was no disagreement.

But, inevitably, the well-known personal qualities which industry, and indeed every employer of graduates, is looking for were reviewed, and there was an uneasy feeling that industry, in its anxiety to find graduates who can readily accommodate themselves to team-work, is placing too much emphasis on a pleasant personality and is in danger of excluding graduates with original minds. After some misunderstanding about the employment of the graduate of modest abilities on development work rather than on research, it was agreed that first-class men are needed for both, but that more men of modest abilities can be employed on development work, once it has been planned, than on research. An interesting point, which unfortunately was not considered in any detail, is the tendency of university courses to develop analytical, rather than constructive, thinking, and it was suggested that the tendency is stronger in pure science than in engineering.

On the whole, there was singularly little criticism of first-degree courses. The Conference was in sympathy with the professor who said that it was not sufficient to allow, as had been suggested, new knowledge to be concentrated by some natural process into simple principles, so lightening the courses. He favoured 'disarmament conferences' for reducing the content of the curricula, at least in engineering. The extension of first-degree courses from three to four years was briefly discussed, but received little support, mainly because the advantages it offers are outweighed by the fact that it will make the shortage of scientists and engineers even more acute.

The Conference found that it was quite impossible to discuss first-degree courses without quickly running up against the problem of the shortage of scientific and technical man-power; indeed, this became the background to all discussions. It is appropriate, as one research director put it, that the Conference should be thinking of ways of improving first-degree courses and the training given to graduates in the universities and in industry; but the most important question at the moment is how to find more boys of the present quality to read seience and engineering. The Ministry of Education's report, "Early Leaving", suggests that the possibility of diverting boys from arts to science is not very great. The main hope lies in preventing early leaving. There may be as many as five thousand boys in Great Britain who leave the grammar schools at sixteen, but who would have been capable of studying at least two science subjects up to the Advanced level of the General Certificate of Education. One of the discussion groups directed attention to the great attraction that the Oxford and Cambridge classical scholarships have for the ablest boys, many of whom would have done equally well on the science side; but it was pointed out in the open discussion by a professor of chemistry that industry has it in its power to redress the balance between the number of arts and science scholarships at the universities, if this is thought to be unsatisfactory.

Mr. C. Paine (Imperial Chemical Industries, Ltd.) and Mr. O. W. Humphreys (General Electric Co., Ltd.) were the opening speakers in the third session, the subject being the selection and training of graduate research staff in industry. Mr. Humphreys deprecated what he termed the university scramble, in which firms, including his own, participate by sending representatives to the universities to recruit science and engineering graduates, and it was natural that this should be the starting point for the discussion groups. Everyone thought that the university scramble is unedifying and tending to get out of hand; but scarcely any really practical suggestions for removing the worst excesses were put forward. It was pointed out that a certain proportion of students go up to the universities having already decided on the career they intend to follow. If this proportion could be increased by making industry better known in the schools, selection would be easier. The university appointments boards through careers libraries help the student to make up his mind about careers, and their efforts are, or could be, reinforced by vacation courses, works visits and lectures by industrialists to faculty societies. There are apparently a few research directors who do not join the university scramble, and they experience no greater recruitment difficulties than those who do. The majority, however, look upon the scramble as a necessity, if only of self-defence. After remarking that it is the student that selects the firm, and not the firm the student, the chairman of the session, Sir Norman Kipping, accepted the suggestion of one 
of the discussion groups that the Federation of British Industries should examine the problem.

"The training of graduate research staff in industry proved to be a somewhat intangible subject. Mr. Paine himself pointed out that, as compared with such matters as human relations in industry, it has not yet received much attention. It is further complicated by the fact that the training varies according to whether the graduate is a scientist or an engineer, and whether he is employed in a large or a small firm. The two-year apprenticeship for engineering graduates who are later to be engaged on research and development was held by some members of the Conference to be stultifying. As for the size of firms, this may be such that no training can be offered, in which case it is necessary to recruit men who have been in other firms. There appears to be nothing comparable for scientists, whose training is organized scarcely at all. Apparently, in certain firms the young graduate is given a range of problems and is permitted to select one for himself; in others, he is given a particular problem in applied research and told that a solution is wanted within a certain time.

The final session was a discussion on postgraduate training at the university, which was opened by Prof. H. W. Melville (Birmingham) and Prof. A. J. S. Pippard (Imperial College of Science and Technology, London), who dealt with the subject from the science and engineering points of view, respectively. The difference in their two points of view was so striking as almost to suggest that there were two quite separate subjects to be considered. Beginning with postgraduate training in science, the first question to be discussed was whether it is necessary for the young graduate to spend three years at the university on postgraduate training. Industry, it was said, can train him in a shorter period, and indeed the postgraduate course formerly lasted only two years. Apparently the length of postgraduate training depends on the particular science in which the graduate is doing research; that it has extended from two to three years is due to the complexity of modern research apparatus and the need for the student to master new techniques. It might be possible to shorten the postgraduate course if the universities could employ technical assistants on the scale on which they are employed in industry.

On the other hand, if it is true that the working life of the industrial scientist in the purely scientific field is about twenty years, even two years of postgraduate training represents 10 per cent of this period, and a longer course has therefore to be justified. It is also reasonable to ask whether the universities are themselves retaining too many young scientists. This question is not a simple one. Figures for the numbers of young science graduates remaining at the universities for further study and research are quite misleading, as these students leave the univergitios two or three years later and many of them enter industry. The number permanently retained by the universities is very small indeed, probably less than 2 per cent of the output. Further, although the proportion of newly qualified graduates remaining at the universities for postgraduate work may be as high as one in three, this does not mean that invariably all the ablest graduates decide to do postgraduate research. In fact, some of them prefer to go straight into industry.

The discussion on postgraduate training in engineering centred mainly on the need for a small number of young engineers in industry to return to the universities for advanced courses or research. The need is recognized by industry; but the present shortage of scientific and technical man-power makes it very difficult for firms to release staff for long periods. Although industry is hopeful that the position may be easier in the not-too-distant future, at present it favours short courses. Immediate postgraduate training for engineers found little support at the meeting. It was even suggested that the practice of university engineering departments of requiring postgraduate students to have had industrial experience might be followed in other faculties, at least as far as some of their staff are concerned. Nevertheless, there was a plea for an additional year, either as part of the degree course or immediately postgraduate, for the potential research engineer who needs an introduction to modern physics in order that he should understand and be able to use the latest research tools.

The discussion closed with further references to industry's shortage of scientific and technical manpower. First, it was felt that this is being made more acute by the strong attractions of government establishments and of those firms engaged on governmentsponsored work. In consequence, the best young scientific brains are being concentrated in limited sections of the national effort to the detriment of the country as a whole. Second, and even more disturbing, it was said that the shortage of scientific man-power will last at least twenty-five years. All employers of scientists-industry and the universities alike-will have to adjust their affairs accordingly.

\section{THE BUBBLE CHAMBER}

$$
\text { BY DR. C. DODD }
$$

Physics Department, University College, London

$\mathrm{U}$ NTIL recently, two methods were available for the analysis of collision events produced by high-energy particles: the photographic emulsion reveals the tracks in the form of sensitized solid grains, and the cloud chamber produces tracks in the form of tiny liquid drops in a gas. The third and most recent method of detection, the bubble chamber, exhibits the tracks in the form of strings of tiny bubbles in a superheated liquid, and thereby combines the high stopping power of the photographic emulsion with the easy scanning of the cloud chamber photographs. Moreover, the chamber possesses certain characteristics, such as rapid recycling and freedom from distortion and unwanted background, which are particularly desirable.

Dr. D. A. Glaser ${ }^{1}$, of the University of Michigan, discovered in 1952 that a liquid could remain strongly superheated in a clean chamber for several seconds, in the absence of radiation, before the onset of boiling; but that boiling was immediate in the presence of a radioactive source provided the degree of superheat exceeded a certain value. The radiation ionizes the liquid, producing microscopic bubbles carrying like charges, the effect of the charge repulsion being to tend to cause each bubble to increase in size, in opposition to the surface tension effect which tends to make the bubble collapse. For a certain degree of superheat and for a certain degree of ionization, all bubbles, no matter how small initially, grow continuously to a finite size. The degree of superheat is conveniently expressed as the difference between the saturation vapour pressure at the tem- 